\title{
A fungus among us: the Neurospora crassa circadian system
}

\author{
Martha Merrow ${ }^{a, *}$, Till Roenneberg ${ }^{a}$, Giuseppe Macino $^{b}$ and Lisa Franchi $^{b, c}$
}

\begin{abstract}
Neurospora crassa is the only molecular genetic model system for circadian rhythms research in the fungi. Its strengths as a model organism lie in its relative simplicity—compared to photosynthesizing and vertebrate organisms, it is a stripped-down version of life. It forms syncitial hyphae, propagates and reproduces, and the circadian clock is manifest in numerous processes therein. As with other model circadian systems, Neurospora features a transcription/translation feedback loop that is fundamental to an intact circadian system. The molecular components of this loop converge with those of blue light photoreception, thus bringing the clock and one of its input pathways together.
\end{abstract}

Key words: circadian rhythm / frequency / Neurospora crassa

(C) 2001 Academic Press

\section{A circadian system in a fungus}

Poor Brandt! He was the first to observe irregularities in Neurospora crassa growth patterns ${ }^{1}$ but it was the circadian pioneer, Colin Pittendrigh, who demonstrated that these development patterns are a manifestation of a circadian clock. ${ }^{2}$ In doing so, he set the stage for development of a fungal model organism for molecular genetic studies on circadian rhythms.

The fungi are a richly diverse collection of sessile poikilotherms. They extract what they can from their immediate environment, and are subject to the extreme conditions of nature. Thus, there is an obvious selective advantage for possessing an endogenous

From the ${ }^{a}$ Institute for Medical Psychology, University of Munich, 80336 Munich, Germany, ${ }^{b}$ Dipartimento di Biotecnologie Cellulari Ed Ematologia, Università di Roma, 00185 Rome, Italy and ${ }^{c}$ Department of Biology, New York University, New York, NY, USA. *Corresponding author. E-mail: martha@imp.med.uni-muenchen. de

(C) 2001 Academic Press

1084-9521/01/040279+07/\$35.00/0 timing system with which to anticipate the regular, daily changes in temperature, humidity and light. Circadian rhythms are thought to arise from exactly this sort of timing system, one which essentially prepares an organism for the coming dawn. Basic characteristics of these rhythms include self-sustained rhythmicity in constant conditions, a period of about $24 \mathrm{~h}$, stability of the period of the oscillation in different temperatures and nutritional conditions (temperature or nutritional compensation) and entrainment of the oscillation to the environment. ${ }^{3}$ None of these characteristic properties are completely understood at the molecular level in any model system. Indeed, it is not at all clear why a selfsustained rhythm is necessary, given that environmental signals (especially light) are dependable and that a rapidly damping oscillation would serve equally well. ${ }^{4}$

Investigations into rhythmicity in the fungi have most often utilized spore formation, a discrete developmental event which is easily measured. The earliest of these studies were performed with Pilobilus, which conveniently shoots its spores with great force (up to a full $2 \mathrm{~m} !) .{ }^{5}$ Inconveniently, however, Pilobolus prefers dung for satisfying its particular nutritional requirements. Although a substitute media was described, circadian rhythms research moved on to a less demanding fungus, the ascomycete Neurospora crassa. $N$. crassa is a filamentous fungus which prefers warm, moist climates. Collections from nature are most successful between the latitudes $30^{\circ}$ north or $10^{\circ}$ south, though there are other Neurospora species that are found over an even wider range. ${ }^{6}$ Neurospora grows well on defined media, and it became an ideal organism, historically, for numerous genetic endeavors. As a result, the genome is extensively mapped by classical means ${ }^{7}$ and this information was recently supplemented by US and German genome sequencing projects (http://www-genome.wi. mit.edu/annotation/fungi/neurospora/, http: //www.mips.biochem.mpg.de/proj/neurospora/ ).

One of the most versatile tools for screening $N$. crassa mutants is the race tube, first described in $1943 .^{8}$ The race tube is a glass tube into which solid 
media is introduced. Inoculation of the fungus at one end initiates its growth along the length of the tube, at an approximately linear rate. Thus, mutations which reduce fitness by hindering growth rate are easily identified by visual inspection.

Another feature of Neurospora that was utilized for early genetic studies is its abundant production of conidia or asexual spores (See Figure 1). Neurospora growth and development includes asexual propagation, as well as sexual reproduction. The propagation state is characterized by linear growth of vegetative hyphae and conidia formation. The accumulation of orange, carotenoid-rich conidia is impressive under many conditions and its alteration or absence is, like linear growth rate, an easy visual screen. Using race tubes to study conidia formation has been the key for circadian research in Neurospora [Figure 1(b)]. Specifically, growth from one end of a race tube to the other takes days or weeks and about once per $22 \mathrm{~h}$ in constant darkness the circadian system dictates the switch from vegetative growth to asexual development, resulting in discrete accumulations of conidia (bands). The period of band formation does not change significantly between $20^{\circ} \mathrm{C}$ and $30^{\circ} \mathrm{C}$ and, therefore, is called temperature compensated. Rhythmicity persists without damping in constant darkness, though not in constant light, and is readily entrained by blue light. Thus, Neurospora satisfies the criteria for experimental research on circadian rhythms.

\section{Molecular dissection of the circadian system in Neurospora}

A number of genes were identified in screens for clock mutants in Neurospora, one of whichfrequency $(f r q)$-was recovered multiple times. ${ }^{9,10}$ The frq mutants cover the range of phenotypes that one would expect of a defective central clock component: long and short free-running periods and arrhythmicity, loss of temperature and nutritional compensation and differences in entrainment properties to light. ${ }^{11}$ Cloning and sequencing the gene gave little information as to how it achieves these feats ${ }^{12}$ but a number of key experiments demonstrate some of its biochemical and genetic properties. FRQ protein moves between the nucleus and cytoplasm ${ }^{13}$ and is phosphorylated in a timeof-day specific manner. ${ }^{14}$ The phosphorylation regulates the half-life of the protein and also impacts the circadian period. ${ }^{15}$ Phosphorylation has been

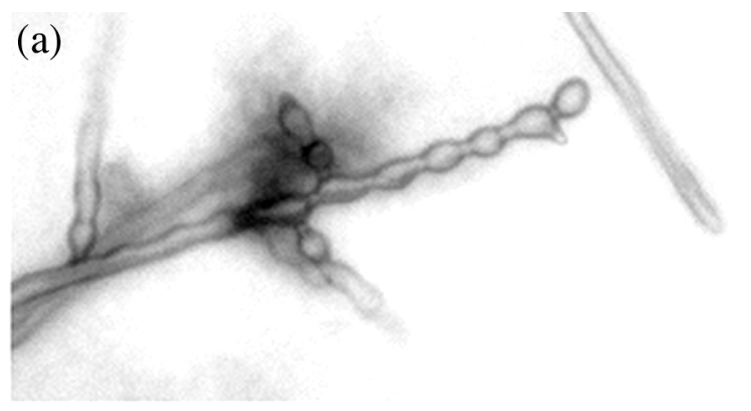

(b)

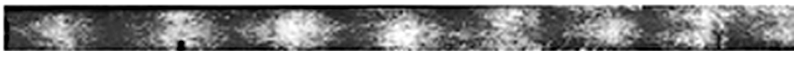

Figure 1. (a) Asexual propagation by Neurospora involves elaboration of conidia on aerial hyphae. This micrograph shows formation of constrictions which segregate one or more nuclei into compartments. The final stage is complete separation of these units- the conidia-and their dispersal. Germination of conidia and growth of vegetative hyphae precede a subsequent round of conidial development (Reproduced with permission from Reference 60). (b) A race tube. The $b d A$ strain (the generic wild type for circadian rhythms research) was inoculated at the left end. The filamentous fungus grows along the length of the race tube at an approximately linear rate. Areas of decreased pixel density are masses of aerial hyphae and conidia which accumulate about once per $22 \mathrm{~h}$ in constant darkness and punctuate the lawn of vegetative hyphae.

implicated in determining the activation state of many proteins, including transcription factors, in general, as well as the subcellular localization of proteins. ${ }^{16,17}$ Thus, it is possible that the multiple phosphorylation states of the FRQ protein could have numerous functions.

FRQ negatively regulates its RNA expression levels, ${ }^{18}$ and this feedback is believed to be the basis for circadian oscillations in RNA and protein levels that is characteristic for gene expression of many central clock components. ${ }^{14,19,20}$ Indeed, constitutive $f r q$ RNA expression in constant conditions results in loss of rhythmic conidiation. ${ }^{18}$ Although specific details between species differ, the frq regulatory (endogenous and exogenous) profile has features characteristic of a transcription/translation feedback loop, which is common to all circadian systems described genetically so far.

frq RNA was characterized for its behavior in response to light, a finding that should provide insights into entrainment of the circadian system by the environment. The RNA is induced rapidly by light, in a dose-dependent manner correlating with shifting the phase of the clock. ${ }^{21}$ frq can be light- 
induced to equivalent levels at all times of day, ${ }^{21,22}$ consistent with the ability of light to induce large phase shifts at certain times of day (a type 0 phase response curve ${ }^{11}$ ).

\section{Light input meets the clock}

The rapid light induction of $f r q$ RNA suggests that the gene is not far downstream of the light input components. How close is $f r q$ to the light input pathway? Experiments to address this question were facilitated by extensive studies from the past several decades that identified components-two single loci-which mediate the developmental and morphological responses of Neurospora to blue light. Neurospora is considered an ideal genetic system for the study of light signal transduction because there is a collection of distinct morphological outcomes following exposure to blue light, with no responses so far documented to red light. The $w c-1$ and $w c-2$ single mutants are impaired in almost all light-specific functions, showing a dark-grown phenotype in the presence of light. ${ }^{7,23-25}$ Sequence analysis, as well as DNA binding experiments, indicate that the WC proteins are zinc finger transcription factors. ${ }^{26,27}$ In addition, genetics and physiological studies suggest that WC-1 and WC-2 positively regulate the expression of the light-induced genes. The proteins also feature multifunctional PAS domains, which are protein-protein interaction domains that are commonly found both in proteins that sense environmental changes 28,29 and in many clockassociated molecules. ${ }^{30,31}$ One of the WC-1 PAS domains was classified as a LOV (light oxygen voltage sensing) domain. ${ }^{32}$ The homologous region in the plant blue light photoreceptor NPH1 binds flavin mononucleotide, a chromophore that is likely to mediate light-dependent autophosphorylation. ${ }^{33}$ According to classical photobiology studies, a flavin is also the predicted chromophore for the Neurospora photoreceptor. $^{34}$ Given that WC-1 and WC-2 are assembled in a white collar complex (WCC) in both the presence and absence of light, ${ }^{35}$ it is possible that one of these proteins, or the complex itself, acts as a photoreceptor molecule.

Responses that are impaired in the $w c$ mutants include the light induction of $f r q,{ }^{36}$ suggesting that light input to the clock is mediated by the WC proteins. Genetic and biochemical evidence indicates how this transduction pathway functions. WC-1 and WC-2 are necessary for activation of $f r q$

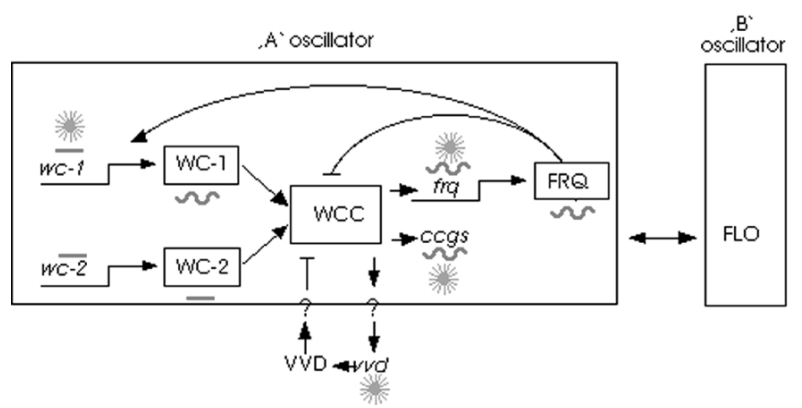

Figure 2. Molecular components of the N. crassa circadian system. A transcription/translation feedback loop is formed by the $f r q, w c-1$ and $w c-2$ gene products. These components are necessary for a self-sustained oscillation in constant darkness (DD) as well as synchronization of the circadian output, conidiation, by light. In our model, these could function as the 'A oscillator' described by Pittendrigh. ${ }^{3}$ Additional oscillatory machinery exists independently of the transcription/translation loop, alternately called the FLO (FRQ-less oscillator ${ }^{61}$ ) or the 'B oscillator' 3 or the rhythm generator. ${ }^{4}$ The vvd gene product regulates light input pathways. ${ }^{43}$ ccgs refers to downstream genes (clock controlled genes) that are regulated by the clock and thereby do its work. Wavy line indicates rhythmic expression in DD; straight line is non-rhythmic; sun is lightinduced. See text for abbreviations. Adapted from Trends in Genetics, vol. 17, Merrow \& Roenneberg, "The circadian cycle: is the whole greater than the sum of its parts?”, pp. 47, copyright 2001, with permission from Elsevier Science.

transcription and for self-sustained rhythmicity. ${ }^{36}$ Given that $f r q$ is weakly expressed in $w c-1$ and $w c-2$ mutant strains, the WC proteins may function as the transcriptional activators necessary for the positive aspect of the transcription/translation feedback loop (see Figure 2). In this model, the WCC activates frq transcription in constant conditions until the FRQ protein accumulates and acts to repress its own synthesis, perhaps by interacting with the WCC, thus providing a mechanism for self-sustained rhythmicity. Support for this configuration comes from interdependent regulation of $f r q$ and $w c-1$ by their proteins, and a circadian regulation of the WC-1 protein product. ${ }^{22,37,38}$ Indeed, frq expression is not simply downstream of the WCC, but is necessary for the accumulation of $w c-1 \mathrm{RNA}^{22}$ and protein product. ${ }^{22,37}$ It was also shown that FRQ complexes with the WC proteins, ${ }^{22,39}$ with WC-2 mediating the interaction of WC-1 and FRQ in a multimeric complex. ${ }^{39}$

The role of FRQ in the regulation of the light response is further clarified by the finding that the presence of FRQ per se (i.e. constitutively expressed), 
and not a FRQ/frq negative feedback loop, permits regulation of conidiation by light. ${ }^{22}$ In the absence of FRQ all light-induced conidial banding is absent. ${ }^{40-42}$ Other light-induced physiologies persist without FRQ although there is a deficit in overall levels. ${ }^{42}$ Finally, the strength of light responsiveness, measured both for gene expression and carotenoid induction, depends on the circadian time, suggesting that the light input pathway is modulated by the clock. ${ }^{22,43}$ This is apparently a common feature of circadian systems, with circadian regulation of light input in Drosophila, ${ }^{44}$ in the marine unicell Gonyaulaux, ${ }^{45,46}$ and in plants. ${ }^{47}$ Light input is not simply a linear transduction of signal to an oscillator, but rather an active mechanism which is itself circadianly regulated.

The problem that we are left with is how to characterize the circadian system on the molecular level: what is input, what is rhythm generator? The data concerning FRQ allow various hypotheses, including FRQ as rhythm generator or FRQ as input component to a downstream rhythm generator. ${ }^{48}$ In Arabidopsis thaliana numerous photoreceptor molecules are period mutants: they have aberrant free running periods in constant conditions. ${ }^{49}$ Further, the photoreceptors are transcription factors. ${ }^{50}$ But in this plant model system, there are several candidates for components of a rhythm generator that are independent of the light input pathways. ${ }^{20,51,52}$ To date a similar component remains unknown in Neurospora, but physiological experiments suggest that an additional circadian machinery exists independent of the transcription/translation loop ('A' oscillator, see below) portrayed in Figure 2. ${ }^{42}$

\section{Unique insights from Neurospora}

The original description of the 'arrhythmic' $f r q^{9}$ strain ${ }^{53}$ in 1986 reports that under special conditions its conidiation is rhythmic, with a free-running period in the circadian range (see Figure 3, redrawn from Reference 54), demonstrating that oscillations in this time range can occur without functional FRQ protein. This important observation, which suggests FRQ-independent oscillatory behavior, has only recently been investigated further. Experiments using mutants in lipid metabolism pathways were characterized for their periodicity and shown to have extremely long periods in constant conditions (typically 35 to $100 \mathrm{~h}$ ), ${ }^{40}$ with or without FRQ. The possibility that this rhythmicity is related to the circadian clock mechanism is suggested by the

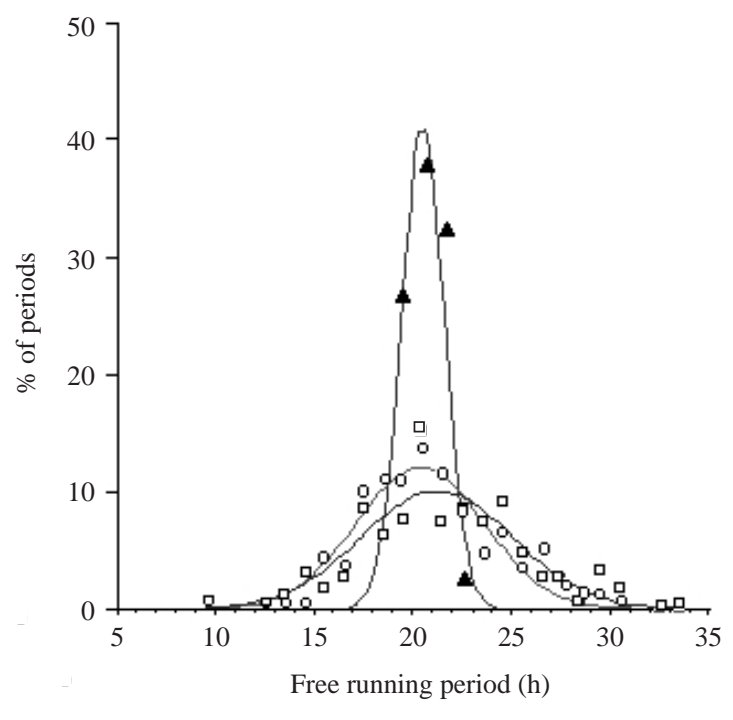

Figure 3. Determination of free running period in $f r q$ mutants (reanalysed based on data from Reference 54). The individual periods of conidial band formation are plotted according to their distribution and fitted for a Gaussian distribution. The period of $\mathrm{frq}^{+}$(full triangle) is $20.6+/-1.1 \mathrm{~h}, r=0.99 ; f r q^{9}$ open square), $21.2+/-$ $3.6 \mathrm{~h}, r=0.88$; $f r q^{10}$ (open circle), $20.4 \mathrm{~h}+/-3.22$, $r=0.96$. Although on average the periods of the three strains are indistinguishable, clearly in the absence of FRQ stability and precision are lost. Also, the rhythmicity in the null mutants is seen only under special conditions, and it is neither temperature nor nutritionally compensated. ${ }^{10,54}$

titration of appropriate supplements into the race tube media, which results in a systematic titration of the period to the circadian range. When the media is adequately supplemented to a point where growth rate is normal, the free running period reflects that of the frq allele.

The second line of evidence for the existence of circadian machinery independent of the frq transcription/translation loop comes from entrainment experiments with temperature and light. In the absence of FRQ entrainment of conidiation by light is not apparent, ${ }^{40-42}$ consistent with the close interaction of FRQ with dedicated light input pathway components. However, temperature cycles (alternating between $22^{\circ} \mathrm{C}$ and $27^{\circ} \mathrm{C}$ ) will entrain conidiation in these clock mutants. ${ }^{42}$ That the underlying oscillatory machinery is only capable of a weak oscillation is indicated by the inability to achieve a 'frequency demultiplication', a phenomenon that occurs when entraining cycles are half of the free-running period and the oscillation is robust enough to consolidate to a period that is 
double the length of the entraining cycle (note: the term frequency as used here has no connection to the frq gene in Neurospora). The strains that are capable of a free-running rhythmicity under 'standard' conditions, e.g. $f r q^{+}, f r q^{1}$ or $f r q^{7}$, will frequency demultiply. That frq deficient strains do not demultiply may reflect an oscillator with a low amplitude or one that is not self-sustained under these conditions.

What does it mean when oscillatory features such as entrainment and free-running rhythmicity are observed in the absence of a central clock component such as FRQ? One explanation is that the oscillations are simply non-circadian, and in the intact system, one would never see them, and they need not be considered further with regards to the clock mechanism. This view has been taken ${ }^{55}$ based on a lack of temperature and nutritional compensation in the rhythmicity of the frq null strains. ${ }^{10,54}$ An alternative view places the FRQ transcription/translation feedback loop upstream of the actual rhythm generator, with the clock gene exerting its effect on the circadian system in constant conditions as an endogenously regulated sensory input pathway. ${ }^{22,42,48,56}$

Yet another possibility recalls classical experiments performed with Drosophila pseudoobscura and its eclosion rhythm. Protocols using either a temperature or a light pulse resulted in distinctly different patterns of phase shifting. ${ }^{3}$ The interpretation of these experiments was that the circadian system is composed of two oscillators. One (the A oscillator) is light-entrained and is generally the pacemaker, and the other (the B oscillator) can be entrained by temperature and is normally difficult to distinguish individually. If this model applies to Neurospora, why are there no known components of the B oscillator? None of the mutant screens which have been used to date have attempted to distinguish $\mathrm{A}$ versus $\mathrm{B}$ oscillators, so, by default, they are biased to reveal genes that encode the major components of the A oscillator. On the other hand, the very nature of the $\mathrm{B}$ oscillator is problematic to characterize on almost any level, given that, in the intact system, it is normally a slave to the A oscillator, and in the absence of $\mathrm{A}$ it is not very robust, so reluctant that it requires entraining cycles to get something going.

The A and B oscillator model is an elegantly parsimonious explanation for complex and confounding physiologies. The molecular genetic era has streamlined circadian systems further, maybe even too far: in the case of Neurospora, all circadian properties are in some way regulated by a single gene. FRQ confers entrainment by light, temperature and nutritional compensation, free-running periodicity, etc. That it is central to an intact and robust system is without question, however, it could be but one part of a complex network of loops that have, for example, been proposed to represent cellular pathways. ${ }^{57}$ In this scenario, the transcription/translation feedback loop would be but one of a series of loops, which together produce circadian physiology. Further, if FRQ is part of a light input pathway, this would not exclude the existence of additional feedback loops that modify the light response in other ways. Heintzen et al. ${ }^{43}$ argue that such interconnected loops would be redundant, but modelling tells us that each could serve a distinct purpose, namely facilitating stable, temperature compensated circadian rhythmicity. 4,58 Clearly, the circadian oscillation must be insulated from transient variations, and FRQ seems to fulfill this function: in the absence of FRQ a circadian free-running period is seen, but it is less precise (See Figure 3, redrawn from Reference 54). Perhaps the next step is to determine how FRQ integrates various signals from metabolism: indications are that cellular redox state fluctuates with onset of conidia formation in Neurospora. ${ }^{59}$ Why couldn't a flavin molecule, tuned to pick up photons, just as well accept electrons from programmed (circadian) biochemical processes in the cell?

\section{Acknowledgements}

This work is dedicated to Drs Arnold Katz and Thomas Kennedy, talented clinicians with scientific minds, who connect basic research to real life. The authors thank Dr Pat Lakin-Thomas for her insightful critique of the manuscript. This work was supported by the DFG to T.R. and the Meyer-StruckmannStiftung and Eppendorf to M. M. and T. R.; MURST Cofin 99 and Cenci Bolognetti to G. M.

\section{References}

1. Brandt WH (1953) Zonation in a prolineless strain of Neurospora. Mycologia 45:194-208

2. Pittendrigh CS, Bruce VG, Rosensweig NS, Rubin ML (1959) Growth patterns in Neurospora crassa. Nature 184:169-170

3. Pittendrigh CS (1960) Circadian rhythms and the circadian organization of living systems. Cold Spring Harb Symp Quant Biol 25:159-184

4. Roenneberg T, Merrow M (1999) Circadian clocks and metabolism. J Biol Rhythms 14:17-27 
5. Schmidle A (1951) Die Tagesperiodizität der asexuellen Reproduktion von Pilobolus spaerosporus. Arch Microbiol 16:80-100

6. Turner BC, Perkins DD, Farifield A (2001) Neurospora from natural populations: a global study. Fung Gen Biol 32:67-92

7. Perkins DD, Radford A, Newmeyer D, Björkman M (1982) Chromosomal loci of Neurospora crassa. Microbiol Rev 46:426-570

8. Ryan FJ, Beadle GW, Tatum EL (1943) The tube method of measuring the growth rate of Neurospora. Am J Bot 30:784-799

9. Feldman JF, Hoyle MN (1973) Isolation of circadian clock mutants of Neurospora crassa. Genetics 75:605-613

10. Loros JJ, Richman A, Feldman JF (1986) A recessive circadian clock mutation at the frq locus of Neurospora crassa. Genetics 114:1095-1110

11. Dharmananda S (1980) PhD thesis, University of California, Santa Cruz, CA

12. McClung CR, Fox BA, Dunlap JC (1989) The Neurospora clock gene frequency shares a sequence element with the Drosophila clock gene period. Nature 339:558-562

13. Luo C, Loros JJ, Dunlap JC (1998) Nuclear localization is required for function of the essential clock protein FRQ. EMBO J 17:1228-1235

14. Garceau NY, Liu Y, Loros JJ, Dunlap J (1997) Alternative initiation of translation and time specific phosphorylation yield multiple forms of essential clock protein FREQUENCY. Cell 89:469-476

15. Liu Y, Loros J, Dunlap JC (2000) Phosphorylation of the Neurospora clock protein FREQUENCY determines its degradation rate and strongly influences the period length of the circadian clock. Proc Natl Acad Sci USA 97:234-239

16. Thomson S, Mahadevan LC, Clayton AL (1999) MAP kinasemediated signalling to nucleosomes and immediate-early gene induction. Semin Cell Dev Biol 10:205-214

17. Zhu J, Shibasaki F, Price R, Guillemot JC, Yano T, Dotsch V, Wagner G, Ferrara P, McKeon F (1998) Intramolecular masking of nuclear import signal on NF-AT4 by casein kinase I and MEKK1. Cell 93:851-61

18. Aronson BD, Johnson KA, Loros JJ, Dunlap JC (1994) Negative feedback defining a circadian clock: autoregulation of the clock gene frequency. Science 263:1578-1584

19. Xu Y, Mori T, Johnson CH (2000) Circadian clock-protein expression in cyanobacteria: rhythms and phase setting. EMBO J 19:3349-3357

20. Wang ZY, Tobin EM (1998) Constitutive expression of the CIRCADIAN CLOCK ASSOCIATED 1 (CCA1) gene disrupts circadian rhythms and suppresses its own expression. Cell 93:1207-1217

21. Crosthwaite SK, Loros IJ, Dunlap JC (1995) Light-induced resetting of a circadian clock is mediated by a rapid increase in frequency transcript. Cell 81:1003-1012

22. Merrow M, Franchi L, Dragovic Z, Görl M, Johnson J, Brunner M, Macino G, Roenneberg T (2001) Circadian regulation of the light input pathway in Neurospora crassa. EMBO J 20:307-315

23. Harding RW, Shropshire W (1980) Photocontrol of carotenoid biosynthesis. Annu Rev Plant Physiol 31:217-238

24. Degli-Innocenti F, Russo VE (1984) Isolation of new white collar mutants of Neurospora crassa and studies on their behavior in the blue light-induced formation of protoperithecia. J Bacteriol 159:757-761

25. Linden H, Rodriguez-Franco M, Macino G (1997) Mutants of Neurospora crassa defective in regulation of blue light perception. Mol Gen Genet 254:111-118

26. Ballario P, Vittorioso P, Magrelli A, Talora C, Cabibbo A,
Macino G (1996) White collar-1, a central regulator of blue light responses in Neurospora, is a zinc finger protein. EMBO J 15:1650-1657

27. Linden H, Macino G (1997) White collar-2, a partner in blue-light signal transduction controlling expression of lightregulated genes in Neurospora crassa. EMBO J 16:98-109

28. Lindebro MC, Poellinger L, Whitelaw ML (1995) Proteinprotein interaction via PAS domains: role of the PAS domain in positive and negative regulation of the $\mathrm{bHLH} / \mathrm{PAS}$ dioxin receptor-Arnt transcription factor complex. EMBO J 14: 3528-3539

29. Zhulin IB, Taylor BL, Dixon R (1997) PAS domain S-boxes in Archea, Bacteria and sensors for oxygen and redox. Trends Biochem 22:331-333

30. Rutila JE, Suri V, Le M, So MV, Rosbash M, Hall JC (1998) CYCLE is a second bHLH-PAS clock protein essential for circadian rhythmicity and transcription of Drosophila period and timeless. Cell 93:805-814

31. Ponting CP, Aravid L (1997) PAS: a multifunctional domain family comes to light. Curr Biol 7:674-675

32. Huala E, Oeller PW, Liscum E, Han I-S, Larsen E, Briggs WR (1997) Arabidopsis NPH1: a protein kinase with a putative redox-sensing domain. Science 278:2120-2123

33. Christie JM, Reymond P, Powell GK, Bernasconi P, Raibekas AA, Liscum E, Briggs R (1998) Arabidopsis NPH1: a flavoprotein with properties of a blue light photoreceptor for phototrophism. Science 282:1698-1701

34. Paietta J, Sargent ML (1983) Isolation and characterization of light-insensitive mutants of Neurospora crassa. Genetics 104:11-21

35. Talora C, Franchi L, Linden H, Ballario P, Macino G (1999) Role of a white collar-1-white collar-2 complex in blue-light signal transduction. EMBO J 18:4961-4968

36. Crosthwaite SK, Dunlap JC, Loros JJ (1997) Neurospora wc-1 and $w c-2$ : Transcription, photoresponses, and the origin of circadian rhythmicity. Science 276:763-769

37. Lee K, Loros JJ, Dunlap JC (2000) Interconnected feedback loops in the Neurospora circadian system. Science 289:107-110

38. Cheng P, Yang Y, Heintzen C, Liu Y (2001) Coiled-coil domain medaited FRQ-FRQ interaction is essential for its circadian clock function in Neurospora. EMBO J 20:101-108

39. Denault DL, Loros JJ, Dunlap JC (2001) WC-2 mediates WC1FRQ interaction within the PAS protein-linked circadian feedback loop of Neurospora. EMBO J 20:109-117

40. Lakin-Thomas PL, Brody S (2000) Circadian rhythms in Neurospora crassa: lipid deficiencies restore robust rhythmicity to null frequency and white-collar mutants. Proc Natl Acad Sci USA 97:256-261

41. Chang B, Nakashima H (1997) Effects of light-dark cycles on the circadian conidiation rhythm in Neurospora crassa. J Plant Res 110:449-453

42. Merrow M, Brunner M, Roenneberg T (1999) Assignment of circadian function for the Neurospora clock gene frequency. Nature 399:584-586

43. Heintzen C, Loros JJ, Dunlap JC (2001) The PAS protein VIVID defines a clock-associated feedback loop that represses light input, modulates gating, and regulates clock resetting. Cell 104:453-464

44. Emery P, So WV, Kaneko M, Hall JC, Rosbash M (1998) CRY, a Drosophila clock and light-regulated cryptochrome, is a major contributor to circadian rhythm resetting and photosensitivity. Cell 95:669-679

45. Roenneberg T, Taylor W (1994) Light induced phase responses in Gonyaulax are drastically altered by creatine. J Biol Rhythms 9:1-12 
46. Roenneberg T, Deng T-S (1997) Photobiology of the Gonyaulax circadian system: I different phase response curves for red and blue light. Planta 202:494-501

47. Bognar LK, Adam AH, Thain SC, Nagy F, Millar AJ (1999) The circadian clock controls the expression pattern of the circadian input photoreceptor, phytochrome B. Proc Natl Acad Sci USA 96:14652-14657

48. Roenneberg T, Merrow M (1998) Molecular circadian oscillators-an alternative hypothesis. J Biol Rhythms 13:167-179

49. Somers DE, Devlin PF, Kay SA (1998) Phytochromes and cryptochromes in the entrainment of the Arabidopsis circadian clock. Science 282:1488-1490

50. Martinez-Garcia JF, Huq E, Quail PH (2000) Direct targeting of light signals to a promoter element-bound transcription factor. Science 288:859-863

51. Strayer C, Oyama T, Schultz TF, Raman R, Somers DE, Más P, Panda S, Kreps JA, Kay SA (2000) Cloning of the Arabidobsis clock gene TOC1, an autoregulatory response regulator homologue. Science 289:768-771

52. Roenneberg T, Merrow M (2000) Circadian light input: omnes viae Romam ducunt. Curr Biol 10:R742-R745

53. Loros JJ, Feldman JF (1986) Loss of temperature compensation of circadian period length in the frq-9 mutant of
Neurospora crassa. J Biol Rhythms 1:187-198

54. Aronson BD, Johnson KA, Dunlap JC (1994) The circadian clock locus frequency: a single ORF defines period length and temperature compensation. Proc Natl Acad Sci USA 91:7683-7687

55. Iwasaki H, Dunlap JC (2000) Microbial circadian oscillatory systems in Neurospora and Synechococcus: models for cellular clocks. Curr Opin Microbiol 3:189-196

56. Lakin-Thomas PL (2000) Circadian rhythms: new functions for old clock genes? TIG 16:135-142

57. Kauffman SA (1974) The large-scale structure and dynamics of gene control circuits: an ensemble approach. J Theor Biol 44:167

58. Barkai N, Leibler S (2000) Circadian clocks limited by noise. Nature 403:267-268

59. Hansberg W, de-Groot H, Sies H (1993) Reactive oxygen species associated with cell differentiation in Neurospora crassa. Free Radic Biol Med 14:287-293

60. Foster RG, Lucas RJ (1999) Clocks, criteria and critical genes. Nature Genet 22:217-219

61. McWatters H, Dunlap JC, Millar AJ (1999) Circadian Biology: clocks for the real world. Curr Biol 9:R633-R635

62. Merrow M, Roenneberg T (2001) The circadian cycle: is the whole greater than the sum of its parts? Trends Gen 17:4-7 